\title{
Subjetividade e formação inicial docente no Centro de Ciências e Planetário do Pará
}

\author{
Subjectivity in initial teacher training in the Center of Science and \\ Planetary of Pará
}

\author{
Victtor Takeshi Barreiros Yano ${ }^{1}$ \\ José Moyses Alves² \\ André Luiz Rodrigues dos Santos Cunha ${ }^{3}$
}

\section{Resumo}

Objetivamos investigar como o estágio no Centro de Ciências e Planetário do Pará (CCPP) contribui para a formação inicial de professores de física interpretando os sentidos subjetivos que tem para eles as atividades do estágio, inspirados na teoria da subjetividade de González Rey. Participaram da pesquisa sete monitores do CCPP, que cursavam a licenciatura em Ciências Naturais - Física, pela Universidade do Estado do Pará. Utilizamos questionários, complementos de frases, redação e entrevistas para obter as informações. Realizamos a análise pautados na epistemologia qualitativa. A partir dos resultados, percebemos que o estágio no CCPP os professores em formação 1) aprendem a relacionar teoria e prática, metodologias de ensino e a conviver com os demais monitores; 2) motivam-se a aprender, a ensinar e também enfrentam situações desanimadoras e, 3) constroem sua identidade profissional, estabelecendo metas para sua atuação futura e desenvolvendo conhecimentos importantes para a profissão. Assim, notamos que o estágio contribui para a formação inicial dos professores independente do contexto educativo em que atuará profissionalmente e que a teoria da subjetividade amplia nossa compreensão sobre este processo de formação inicial. Palavras chave: formação inicial; espaços não formais; subjetividade.

\section{Abstract}

We aim to investigate how the internship in the Centro de Ciências e Planetário do Pará (CCPP) contributes to the initial formation of physics teachers interpreting the subjective senses that have for them the activities of the stage, inspired by the theory of subjectivity of González Rey. We participated in the research seven monitors of the CCPP, who studied the degree in Natural Sciences - Physics, by the University of the State of Pará. We used questionnaires, sentence complements, essays and interviews to obtain the information. The

\footnotetext{
${ }^{1}$ Universidade Federal do Pará | takeshi@uepa.br

${ }^{2}$ Universidade Federal do Pará | jmalves@ufpa.br

3 Universidade Federal do Pará | andresymarajr@gmail.com
} 
analysis was based on qualitative epistemology. From the results, we realize that the CCPP internship teachers in training 1 ) learn to relate theory and practice, teaching methodologies and to live with the other monitors; 2) motivate themselves to learn, teach and also face discouraging situations, and 3) build their professional identity, set goals for their future performance and develop important knowledge for the profession. Thus, it was observed that the internship contributes to the initial formation of teachers independent of the educational context in which they will work professionally and that the theory of subjectivity expands our understanding of this process of initial formation.

Keywords: initial formation; non-formal spaces; subjectivity.

\section{Movimentos preliminares}

O presente estudo é uma investigação, inspirada na teoria da subjetividade de González Rey, sobre a influência do estágio no Centro de Ciências e Planetário do Pará (CCPP) para a formação inicial de professores de física.

A formação de professores, hoje, constitui-se um campo de estudo, uma área de conhecimento. Certamente, contribuindo para desvelamento de aspectos importantes para a qualificação da educação (RAMOS et al, 2016). A formação inicial, que acontece ao longo da primeira graduação, é definida em oposição à formação continuada, que acontece, subsequentemente, ao longo de toda a experiência profissional do professor (MIZUKAMI, 2002). A formação inicial, que está em foco neste estudo, vem sofrendo mudanças importantes. Destacamos o papel do estágio durante esta formação, pois antes, ele acontecia apenas no último ano dos cursos de licenciatura após três anos de disciplinas cujos conteúdos não eram diretamente relacionados à prática profissional (BORGES, 2009). Antes, também, o estágio em espaço não formal não era exigido, porque se entendia que ele não traria contribuições para a docência em espaço formal, atuação profissional predominante do professor (CHARÃO, 2004). Atualmente, em alguns cursos, o estágio, que tem como condição fundamental articular teoria e prática, acontece mais precocemente (PIMENTA; LIMA, 2010). Além disso, alguns cursos exigem tanto a experiência do estagiário em espaços de educação formal, quanto de educação não-formal. Este é o caso do curso de licenciatura e do espaço não formal que investigamos no presente estudo. Os estagiários do curso de licenciatura em física da Universidade do Estado do Pará (UEPA) têm em sua grade curricular disciplinas de estágio em espaços de educação não formal e o CCPP é um dos espaços onde esse estágio acontece.

A literatura da área (JACOBUCCI, 2008; GOHN, 2006) apresenta várias diferenciações entre educação formal, não-formal e informal. Apesar de diferentes dos contextos formais e informais de ensino, os contextos não formais também podem ser bem diferentes entre si, por exemplo, em termos da duração de atendimento aos usuários. Nosso lócus não formal de interesse é o CCPP, que se aproxima da concepção dos museus de ciências, cujos visitantes vão esporadicamente e, dependendo de sua livre escolha, participam das atividades que o espaço oferece.

Existem poucas pesquisas sobre os processos de ensino e aprendizagem que acontecem em espaços não formais, assim como sobre a contribuição do estágio para a formação inicial dos professores que neles atuam (MARANDINO, 2006). A partir de uma revisão da literatura encontramos três artigos (CHINELLI; PEREIRA; AGUIAR, 2008; OVIGLI, 2011 e BARBOSA-LIMA; GONÇALVES, 2014) que focalizavam a relação entre formação inicial 
e espaço não formal. Preocupados, primordialmente, com a divulgação da ciência, buscaram criar relações entre museu - escola, desenvolvendo estratégias para favorecer a formação do aluno que os frequenta. Esses trabalhos também investigaram como o professor em formação aprende a mediar as diferentes interações sociais que acontecem nas instituições e a relação dos estudantes com o conhecimento. A aprendizagem de estudantes e de professores em formação são, em geral, concebidas como processos de sujeitos ativos, embora haja uma ênfase na dimensão cognitiva em detrimento de outras dimensões.

Para González Rey (2002, 2005), a subjetividade é um fenômeno complexo, simultaneamente social e individual. Estes dois níveis de organização constituem-se e influenciam-se reciprocamente. A subjetividade é constituída de sentidos subjetivos, que mesclam processos simbólicos e emocionais (re)configurados, permanentemente, na trajetória de vida singular de cada sujeito. Entendemos que, ao utilizar um referencial teórico que supera as dicotomias afetivo-cognitivo, interno-externo, individual-social, podemos ampliar o olhar para a contribuição do estágio em espaço de educação não formal para a formação inicial de professores.

\begin{abstract}
Sentidos subjetivos são verdadeiros sistemas motivacionais que - diferente das teorias mais tradicionais da motivação - permitem-nos representar o envolvimento afetivo do sujeito em uma atividade, não apenas pelo seu vínculo concreto nela, mas como produção de sentidos que implicam em uma configuração única de sentidos subjetivos, emoções e processos simbólicos resultantes de subjetivação que integram aspectos da história individual, como os diferentes momentos atuais da vida de cada sujeito concreto (GONZÁLEZ REY, 2008, p. 34).
\end{abstract}

Portanto, objetivamos no presente estudo investigar as contribuições do estágio no CCPP para a formação inicial de professores de física, considerando a subjetividade dos licenciandos envolvidos no processo, isto é, interpretando os sentidos subjetivos produzidos por monitores de física em relação às atividades que desenvolvem no CCPP.

\title{
A direção tomada
}

O Planetário do Pará "Sebastião Sodré da Gama", foi fundado em 30 de setembro de 1999, vinculado à Universidade do Estado do Pará - UEPA, com a missão de criar possibilidades de melhorias no ensino e aprendizagem de ciências, principalmente, da Astronomia. Em outubro do ano de 2012, o Planetário do Pará ampliou seu campo de atuação, possibilitando o acesso fácil e agradável de estudantes, professores e a comunidade em geral. Foram criados espaços destinados às ciências exatas e da natureza, que incorporaram-se ao Planetário, passando então a compor o Centro de Ciências e Planetário do Pará. Tal ampliação implicou na reformulação dos objetivos do projeto original, que passaram a contemplar, além das ações de extensão, ações de ensino e pesquisa, vinculadas diretamente ao envolvimento de docentes na aplicação de projetos, no espaço do Centro. Atualmente, o CCPP possui, sete ambientes científicos: Cúpula de projeções, Astronomia, Química, Biologia, Matemática, Geologia e Física.

Para investigar os sentidos subjetivos de futuros professores de física, realizamos uma pesquisa qualitativa inspirada na epistemologia qualitativa, proposta por 
Gonzalez Rey (2006), que entende a construção de conhecimento como um processo construtivo-interpretativo, valoriza o diálogo com os participantes da pesquisa e considera legitimo o conhecimento produzido a partir do estudo de caso de sujeitos singulares.

Participaram da pesquisa sete monitores do CCPP, que cursavam a licenciatura em física, sendo três estagiários do próprio centro e outros quatros bolsistas do PIBID (Programa Institucional de Bolsas de Iniciação à Docência). Para preservar suas identidades, atribuímos a eles nomes fictícios de planetas, sendo os bolsistas nomeados como planetas rochosos (Mercúrio, Vênus, Terra e Marte) e os estagiários como planetas gasosos (Saturno, Urano e Netuno).

Realizamos a coleta de informações durante um semestre, utilizando como instrumentos questionários, complementos de frases, redação e entrevistas. A partir das informações, construímos indicadores de sentidos subjetivos e delineamos a configuração de sentidos para cada sujeito. Aproximando essas configurações de sentidos subjetivos, criamos categorias e subcategorias referentes à contribuição do estágio no CCPP para a formação inicial destes futuros professores.

\section{Os resultados alcançados}

Ao interpretar os sentidos subjetivos dos monitores relacionados ao estágio, podemos compreender como eles se envolvem emocionalmente nas atividades e como desenvolvem processos simbólicos pertinentes à sua formação profissional, em suas comunicações com os outros.

Apesar de apresentarem configurações de sentidos subjetivos singulares, podemos encontrar semelhanças e categorizar as diferentes maneiras pelas quais o estágio no CCPP contribui para a formação inicial desses futuros professores.

Nesta perspectiva, podemos afirmar que o estágio no CCPP: 1) proporciona aprendizagens relacionadas à articulação entre teoria e prática, à utilização de metodologias de ensino diferenciadas e à convivência com colegas, orientador e visitantes; 2) motivam a aprender, estudar, refletir e superar dificuldades; a ensinar e, algumas vezes, dificultam o envolvimento dos estagiários nas atividades; 3) auxiliam a construção da identidade profissional, favorecendo o estabelecimento de metas para a futura atuação profissional e atitudes consideradas essenciais para esta atuação.

A seguir vamos apresentar cada uma destas categorias e subcategorias, ilustrá-las com falas de alguns estagiários e comentá-las, dialogando com outros pesquisadores.

\section{O estágio no CCPP contribui para formação inicial pois favorece aprendizagens.}

De acordo com os sujeitos da pesquisa no estágio eles aprenderam a articular teoria e prática, porque nas atividades do CCPP tem contato com estudantes concretos, usam recursos didáticos que facilitam a contextualização dos conteúdos, colaboram com a transposição didática, facilitando o processo de ensino-aprendizagem e tem liberdade para fazer tudo isso, desenvolvendo sua autonomia docente.

O estágio em outros lugares, como o CCPP, nos dá a oportunidade de colocar toda a teoria em prática diariamente, dando uma "maior" liberdade (BOLSISTA TERRA - Q). 
No CCPP vemos grande parte do que aprendemos na pratica, podemos colocar na pratica o que aprendemos na universidade. (ESTAGIÁRIO MERCURIO - Q).

É aplicar conhecimento que aprendemos na faculdade através dos experimentos que temos no centro (MARTE -E).

A articulação teoria e prática é fundamental para que o conhecimento supere e se desenvolva do senso comum ao conhecimento específico, caracterizando o que Freire (2006) denomina como "pensar certo". Trata-se da compreensão de que nenhum conhecimento está pronto e acabado e como seres históricos somos produtores desse conhecimento, que intervém e constrói o mundo. Tal entendimento rompe com amarras históricas que fundamentam uma educação reprodutiva e disciplinadora.

Os espaços de educação não formal, seja pelo acervo que dispõem, ou por suas tendências profissionais, oferece condições para a criação de práticas pedagógicas diversificadas. De acordo com Hooper-Greenhill (1994, p. 04),a abordagem teórico-prática mais comum nos espaços museais é a construtivista "que compreende o conhecimento como algo construído a partir da interação do aprendiz com o ambiente social, e nesse caso, a subjetividade é parte dessa construção".

Essa reflexão vai ao encontro da perspectiva de González Rey (2003), para quem os processos sociais deixam de ser vistos como externos em relação aos indivíduos. Os contextos sociais são concebidos como sistemas complexos, onde o sujeito é constituído e constituinte. Dessa forma, cada momento se configura a partir dos diferentes modos que adquirem as relações entre o indivíduo e o social. A subjetividade é simultaneamente individual, resultado da história singular do sujeito e social, pois essa história singular acontece nos diferentes contextos sociais em que o sujeito participa.

Os monitores também aprenderam no estágio a utilizar metodologias de ensino diversificadas. Termos como transposição didática, diversidade metodológica, prática experimental, inovação e ludicidade estão presentes em suas expressões.

Eu não consigo ensinar se eu não me relacionar com a pessoa, eu não tô ensinando pra uma máquina, tô ensinando a uma pessoa e isso necessariamente precisa ter uma relação. Então toda relação que eu tive aqui, é isso que eu vou levar. As viagens que eu fiz, a forma como interagi com aquela pessoa de lá, isso eu vou levar, porque isso com certeza... eu vou usar em algum momento da minha vida (MERCURIO - E).

Ao ter maior interação com o público no espaço, pude notar um avanço no meu potencial didático, visto que antes da minha chegada no espaço, tinha muitas dificuldades no quesito falar em público, onde a cada dia fui superando, graças às maravilhosas experiências que 0 centro proporcionou (SATURNO - R).

Uma das maiores dificuldades enfrentadas pelos estagiários talvez seja essa, adequar a linguagem de acordo com a faixa etária dos visitantes, entretanto sem perder o rigor do tema e/ou disciplina (TERRA - R).

O contato com outras pessoas, aqueles que estão longe da comunidade acadêmica, e ter a oportunidade de explicar os experimentos para eles foi 
importante, pois, isto contribui de forma significativa para o aprendizado em explicar certos conceitos físicos em espaços não formais (URANO - Q).

O trabalho no CCPP contribui muito para minha didática e na forma de me comunicar e transmitir informações, além de potencializar a criatividade no momento de produzir materiais (VÊNUS - R).

Os sujeitos concordam que o estágio favorece a compreensão de que a metodologia de ensino não pode ser estática. Pelo contrário, é importante dinamizar as estratégias, de forma a adequar ao público com quem se trabalha. Assim parecem concordar com Bordenave e Pereira (1991; p.78) quando afirmam que "não há um método bom para todos. Como a dinâmica interna de cada aluno é diferente da dos demais, uns encontram desafio e satisfação onde outros acham aborrecimento e frustração".

Além disso, ao compreender as vantagens do estágio, "percebe-se como se pode ampliar a atuação do professor, pois a partir da prática levam-se em consideração os anseios, as curiosidades, os questionamentos e a diversidade dos alunos" (MORAES; OLIVEIRA; GOLDSCHMIDT, 2017, p. 27). Assim, o método como estratégia permite até certo ponto que o estagiário inove, seja criativo e transforme suas estratégias de ensino.

Ao ensinar, além de dominar o conteúdo, o monitor do CCPP aprende princípios didáticos mais gerais, como a contextualização, o pluralismo didático, o diálogo e a preocupação com a motivação dos alunos, que em um ambiente que favorece a inovação e a criatividade, resulta na experimentação de diferentes abordagens metodológicas. Segundo González Rey (2003), para transcender o caráter passivo-reprodutivo no processo de ensino e aprendizagem, os professores precisam se conscientizar da importância de conquistar o interesse dos alunos.

Além de articular teoria e prática e propiciar aos estagiários o uso de diferentes metodologias, o estágio no CCPP os ensina a conviver com visitantes, colegas e o orientador

Possibilitou conhecer outras localidades do estado através de viagens para divulgar a ciência, além de visitas de alunos e professores de outras localidades, propiciando um intercambio de experiências (BOLSISTA MERCURIO - R).

No CCPP aprendo a trabalhar em equipe e a todo dia tentar melhorar (ESTAGIÁRIO SATURNO - CF 1).

O contato com outras pessoas, aqueles que estão longe da comunidade acadêmica ...ter a oportunidade de explicar os experimentos para eles foi importante, pois, isto contribui de forma significativa para o aprendizado em explicar certos conceitos físicos em espaços não formais (ESTAGIÁRIO URANO - Q).

Os sujeitos reconhecem que o estágio proporciona a oportunidade de construir conhecimentos a partir da interação com os visitantes, mostrando que o papel da mediação, seja entre os monitores, monitor e orientador ou monitor e visitante gera um enriquecimento teórico e prático para todos os envolvidos. Concordamos com Martins (2005, p. 17) quando afirma que "a mediação se enriquece na troca de pontos de vista de cada um no seu grupo, acrescidos de outros trazidos por teóricos e estudiosos". 
Procurar encantar os visitantes, se relacionar com outros monitores e com o orientador são desafios que favorecem o trabalho em equipe e estimulam os monitores a superarem seus limites e a criarem estratégias diversificadas para as atividades. Oliveira e Moura (2005) ressaltam que os espaços não formais estimulam a aprendizagem dos monitores e que, além da motivação, se estreitam, também, os laços de amizades.

O trabalho em conjunto requer e propicia muitas aprendizagens. É preciso saber escutar e se colocar no lugar do outro, tentando compreender os diversos pontos de vista abandonando a perspectiva egoísta e egocêntrica, procurando formular o melhor argumento possível para aquele momento do diálogo (SCOZ, 2008). Para Tacca (2006, p. 49) "não é possível pensar o processo de aprendizagens fora de uma relação entre pessoas, cujo eixo não seja o processo dialógico". A participação dos sujeitos não depende simplesmente das ações planejadas, mas, também, das inúmeras possibilidades de compartilhamento de ideias entre pessoas no mesmo espaço, favorecendo, assim, a construção conjunta do conhecimento.

\section{O estágio no CCPP contribui para formação inicial, pois favorece a motivação para aprender e ensinar.}

Outra categoria de sentidos refere-se à (des)motivação dos monitores em relação às atividades desenvolvidas no estágio. Essa categoria engloba a motivação para aprender, para ensinar e as situações desanimadoras vivenciadas no estágio.

O estágio no CCPP motiva a aprender, criar, superar obstáculos, promove o esforço, inspira a buscar novos conhecimentos e a motivar os visitantes nas atividades desenvolvidas.

O que me motiva é justamente isso, é a forma como eu posso trabalhar aqui e ter essa liberdade a mais, de poder criar coisas diferentes, poder fazer coisas que possam ta trazendo cada vez mais dinamismo pros alunos, uma coisa mais interativa (BOLSISTA VÊNUS - E).

Esforço-me diariamente por querer sempre me superar (BOLSISTA TERRA - (F 2).

Fico muito feliz de poder estar estudando numa universidade pública e de estar estudando algo que eu gosto, que é Física, é o que eu gosto muito e esse é o gratificante: fazer algo que você gosta e fazer alguém gostar do que você gosta a partir do que você ensina. Eu prioritariamente prezo muito por isso de estar fazendo algo que eu gosto algo que vou ser motivado para estudar e por mais que eu não saiba resolver alguma coisa, naquele momento, eu vou ser motivado a estudar aquilo pra mim resolver (BOLSISTA MARTE - E).

Segundo Alves (2016, p.98), "a motivação para aprender ciências é uma preocupação atual e relevante". A motivação é uma produção subjetiva, simultaneamente simbólica e emocional, que o sujeito realiza diante das possibilidades oferecidas pelas atividades de que participa, tomando por base configurações de sentidos subjetivos, constituídas a partir de suas experiências anteriores, inclusive em outros contextos.

A motivação ligada à aprendizagem está em evidência nos diversos espaços de ensino (formal, não - formal, informal), fazendo com que os professores em formação se superem, recuem e, em alguns casos, cheguem a desistir. Porém, ela tem um papel muito importante 
no processo de formação inicial docente. A partir das análises dos sentidos subjetivos construídos pelos sujeitos da pesquisa, compreendemos que o estágio contribui para a motivação porque coloca os sujeitos em contato com diferentes públicos, gerando nos estagiários a necessidade de se superar. Eles valorizam a motivação dos visitantes e, quando conseguem motivá-los, também se sentem animados à diversificar suas metodologias de ensino. Esse desafio os impulsiona para a criação e não apenas para a reprodução de procedimentos didáticos.

O CCPP é um espaço que proporciona condições para o professor em formação inicial desenvolver sua autonomia, pois, oferece liberdade para criar e uma atmosfera de respeito e diálogo. O monitor constrói seu aprendizado, a partir da superação dos erros, decorrentes de suas próprias decisões.

Além da motivação para a aprendizagem, também interpretamos sentidos subjetivos dos sujeitos em relação à motivação para ensinar. De acordo com as expressões dos bolsistas e monitores, o estágio no CCPP possibilita ensinar a física de modo divertido, prazeroso e lúdico, buscando atrair a atenção dos visitantes, estimulando-os a buscarem novos conhecimentos e sentindo orgulho e satisfação em ensinar e aprender a física. A motivação pode ser entendida como um processo que suscita ou incita uma conduta, que sustenta uma atividade progressiva, que canaliza essa atividade para um dado sentido (BALANCHO; COELHO, 1996), nesse caso, o ensinar.

O que me motiva é justamente isso, é a forma como eu posso trabalhar aqui e ter essa liberdade a mais, de poder criar coisas diferentes, poder fazer coisas que possam estar trazendo cada vez mais dinamismo pros alunos, uma coisa mais interativa (BOLSISTA VÊNUS - E).

O que me motiva aqui dentro são as próprias pessoas que vem aqui, e a gente consegue ver, né? a ideia delas de querer mesmo, realmente querer, um pouco saber o que é ciência e querer passar um pouco esse conhecimento pra elas é bastante motivante (ESTAGIÁRIO SATURNO - E).

Algumas crianças vem, chegam e não ligam, outras estão lá de olho abertão prestando atenção em ti... Ai o que me motiva assim é quando eu consigo é... Chamar atenção de todas elas, até daquela que não tá ligando muito, eu fico muito feliz (ESTAGIÁRIO NETUNO - E).

De acordo com a teoria da subjetividade de Gonzalez Rey (2008), a motivação depende dos sentidos subjetivos que, com base em suas experiências anteriores, o sujeito produz ao participar de uma determinada atividade. Assim, a motivação para ensinar é uma produção subjetiva que, não necessariamente começa no estágio, mas que o sujeito vem produzindo ao longo da sua vida. Entendemos que o estágio em um ambiente não formal como o CCPP representa uma experiência singular para a produção de sentidos subjetivos relacionados com a motivação para ensinar de futuros professores.

Como possuem liberdade para atuar de forma autônoma no processo de ensinoaprendizagem, sentem prazer, satisfação e motivação para ensinar ciências, os monitores têm condições de abandonar a atitude passiva, frequentemente vivenciada na universidade, para tornarem-se parceiros de trabalho do professor/orientador e de seus colegas, envolvendo-se ativamente com o objeto de estudo. A cooperação e a solidariedade são algumas atitudes que aperfeiçoam o senso de cidadania e servem de carga motivacional ao sujeito (LIMA, 2004). 
Os bolsistas consideram que o estágio no CCPP desmotiva quando ocorre a falta de comprometimento de alguns colegas, assim como quando alguns visitantes não respeitam as normas institucionais. Também desanimam quando precisam desenvolver, rotineiramente, a mesma atividade.

Então, eu creio que o que me desmotiva é isso, eu tento a todo momento ter a mentalidade de que não é uma rotina, porque de fato é uma rotina diária de trabalho, mas cada experiência é diferente, porque cada aluno é uma forma de ensinar diferente, uma forma de aprender diferente e também a gente deve ter essa mentalidade de acrescentar, de forma diferente (BOLSISTA MARTE - E).

O que me desmotiva aqui são algumas pessoas que não levam tão a sério o trabalho, eu acho que é um dos principais fatores que me desmotivam aqui dentro (SATURNO - E).

Quando eu me esforço muito e mesmo assim eu não consigo atingir os objetivos tanto nas visitações quanto no geral. Então, isso me desmotiva bastante, porque as vezes eu não consigo fazer o trabalho como eu deveria, porque eu começo a ficar mal (ESTAGIÁRIO NETUNO - E).

A partir da análise dos sentidos dos sujeitos investigados, notamos que todos sentemse desanimados em algum momento do estágio e isso interfere negativamente no processo de ensino-aprendizagem. No estágio a desmotivação resulta de sentidos subjetivos produzidos individualmente, como o cansaço ou desânimo devido o mau funcionamento dos experimentos disponíveis, mas também resulta de sentidos construídos socialmente, como a não cooperação dos monitores nas atividades, a rotina de visitação, problemas familiares.

\section{O estágio no CCPP contribui para formação inicial pois favorece a construção da identidade profissional.}

O estágio favorece o estabelecimento de metas para a futura atuação. Os sujeitos expressaram que o estágio no CCPP ajuda a pensar o ser professor, além de instigar o gosto por produzir e consumir ciência. Eles entendem que o conhecimento pode transformar vidas e que a educação ajuda a mudar o mundo. Fazem planos para o futuro que implicam ser um bom professor, motivar os alunos, fazer pós-graduação e ajudar a família.

Ser um facilitador, exercer o papel não somente de um locutor, ao narrar acontecimentos, comentar tópicos específicos e realizar avaliações: mas principalmente ser um mentor, que auxilia e motiva o aluno no seu processo de ensino-aprendizagem, sempre adotando metodologias que visam a construção e edificação do ensino, aos discentes (BOLSISTA VÊNUS - Q).

O professor é o responsável por repassar aquilo que ele absorveu durante a sua vida acadêmica, ou seja, ele pode ser a "ponte" para um conhecimento (BOLSISTA TERRA - Q). 
Meu plano é, primeiramente esse, me formar, me especializar, ingressar no mestrado, tenho muito esse sonho, no caso da minha família de poder dar uma condição estável para minha mãe. (BOLSISTA MARTE - E).

Ser professor, é aquele que mesmo com muita dificuldade em sua vida pessoal, tenta dar o seu melhor em sala de aula, e este preparo para dar aula vem bem antes do mesmo em si, pois o professor busca informações novas para contextualizar, como o conteúdo da aula e também estuda para ministrar uma aula que os seus alunos consigam compreender (ESTAGIÁRIO URANO - Q).

O estagiário passa a entender que, em seu processo de formação, precisa desenvolver hábitos pedagógicos que favoreçam seu crescimento profissional permanente. Vão tomando consciência de que a (trans)formação de monitor à professor é um processo difícil, longo e sempre inacabado (FREIRE, 2006). Para Freire (2006, p.14) o exercício da docência exige:

Rigorosidade metódica, pesquisa, respeito aos saberes dos educandos, criticidade, ética e estética, corporificar as palavras pelo exemplo, assumir riscos, aceitar o novo, rejeitar qualquer forma de discriminação, reflexão crítica sobre a prática, reconhecimento e assunção da identidade cultural, ter consciência do inacabamento, reconhecer-se como um ser condicionado, respeitar a autonomia do ser educando, bom senso, humildade, tolerância, convicção de que mudar é possível, curiosidade, competência profissional.

As contribuições do CCPP para a construção da identidade profissional, também relaciona-se às virtudes e competências profissionais. Os monitores consideraram que o estágio no CCPP os torna mais organizados, disciplinados, aptos a inovar e lidar com imprevistos. Eles desenvolvem a capacidade de falar em público e a versatilidade para criar alternativas pedagógicas. Tudo isso será valioso em sua atuação profissional futura.

Através do PIBID já tive um bom contato com a sala de aula o que permitiu trabalhar minha postura e didática, controlar o nervosismo e ficar mais à vontade (BOLSISTA VÊNUS - Q).

O reflexo disso foi que eu melhorei um pouquinho a frente em uma apresentação, principalmente na universidade. É... As aulas também, eu melhorei. Os meus slides ficaram muito melhores também nas apresentações a dicção e principalmente a questão da transposição didática. Você conseguir falar com uma criança a mesma coisa que você fala pra um doutorando, ou pra um pós doutorado, é uma coisa incrível! (ESTAGIÁRIO URANO - E).

O que eu vou levar daqui é que eu aprendi muito a lidar com imprevistos, isso é uma coisa muito importante, porque sempre acontece, e se eu não soubesse lidar com isso, eu com certeza não conseguiria resolver alguns tipos de problemas (ESTAGIÁRIO NETUNO - E).

Concordamos com Scoz (2011) que a relação entre subjetividade e identidade docente é indissociável. O sujeito produz sentidos subjetivos em todos os contextos que participa e 
sobre todas as questões de seu interesse. Alguns desses sentidos dizem respeito ao reconhecimento de si mesmo como pessoa ou como professor (identidade pessoal e profissional). Segundo a autora,

temos um momento fundamental dos professores, em que eles se defrontam com suas subjetividades e identidades e que, portanto, podem reconhecer suas próprias crenças, expectativas, valores e atitudes, refletindo sobre elas. Ao mesmo tempo, poderão entrar em contato com estados afetivos que permeiam seus processos de aprender e ensinar, reposicionando-se diante de suas práticas e de seus alunos (SCOZ, 2011, p. 50).

Ao reconhecer que aprendeu a lidar com os imprevistos e com o nervosismo, por exemplo, o professor produz sentidos sobre si mesmo, reconhecendo a transformação que aconteceu em seu (auto)conhecimento.

\section{A chegada: considerações}

A partir das análises, foi possível notar que as metas e formas de atuação estabelecidas pelos sujeitos da pesquisa ainda na graduação, se assemelham ao que Freire (2006) considera como formas de atuação relevantes para o profissional docente. Dessa forma, compreendemos como promissora a influência do CCPP na formação inicial do monitor de Física.

Cada estagiário e o professor-orientador contribui, a sua maneira, para a construção da experiência do estágio e esta experiência de estágio, por sua vez, contribui para que cada sujeito envolvido produza sentidos subjetivos, com base em suas configurações de sentidos subjetivos anteriores.

Os monitores apresentam sentidos subjetivos singulares, que expressam o momento de suas reflexões sobre o estágio em suas trajetórias de vida. Tais diferenças incluem, entre outras, a maneira como percebem o estágio; as expectativas que tinham antes do estágio; as ênfases que atribuem a aspectos das atividades desenvolvidas e as suas participações; às características de suas relações com os outros agentes sociais no CCPP, bem como às dificuldades que enfrentam dentro e fora daquele contexto. Porém, apesar de apresentarem configurações de sentidos subjetivos diferentes, os monitores concordam que o estágio no CCPP contribui positivamente para suas formações, vindo ao encontro de seus planos para o futuro, ajudando a construir sua identidade profissional, articulando teoria e prática, motivando para o exercício da profissão, ensinando conteúdos, metodologias de ensino e a interagir com o orientador, com os colegas e com diferentes tipos de públicos.

Estes resultados sugerem que, na perspectiva dos monitores, o estágio neste espaço não formal, contribui para a sua formação, independente do contexto educativo em que atuará profissionalmente. As aprendizagens, motivações e projeções do profissional que desejam ser não são específicas para o desempenho das atividades no CCPP ou de outro espaço semelhante, mas se aplicam ao profissional professor de uma maneira geral.

Consideramos que a teoria da subjetividade amplia a nossa compreensão sobre o processo de formação profissional. A partir desta teoria, entendemos que a contribuição das atividades do CCPP, assim como de outros espaços educacionais não se restringe à competências intelectuais, mas envolvem a subjetividade e identidade do estagiário, que 
são (re)construídas a partir dos sentidos produzidos em diferentes espaços sociais e estão em transformação permanente.

\section{Referências}

ALVES, J. M. Cultura científica escolar e construção social da motivação. In: S. N. CHAVES.; C. A. F. SILVA.; M. R. BRITO (org). Cultura e Subjetividade: Perspectivas em debate. São Paulo: Editora Livraria da Física, 2016.

BALANCHO, M. J. S.; COELHO, F. M. Motivar os alunos, criatividade na relação pedagógica: conceitos e práticas. 2. ed. Porto, Portugal: Texto, 1996.

BARBOSA-LIMA. M. C. de A. \& GONÇALVES. C. O. O Ensino Não - formal e a Formação de um Professor de Física para Deficientes Visuais. Revista Ensaio, v.16, n. 02, p. 167-183, 2014.

BORDENAVE, Juan D.; PEREIRA, Adair M. Estratégias de ensino-aprendizagem. $12^{\mathrm{a}}$ ed. Petrópolis: Ed. Vozes, 1991.

BORGES, C. Os saberes docentes e a prática de ensino: a escola como lócus central da formação inicial. In ENS, Romilda Teodora (org.). Trabalho do professor e saberes docentes. Curitiba: Champagnat, 2009.

CHARÃO, C. Quem será professor. Revista: Educação. Ed.2015. Disponível em Acesso em Agosto de 2016.

CHINELLI, M. V.; PEREIRA, G. R.; AGUIAR, L. E. V. de. Equipamentos interativos: uma contribuição dos centros e museus de ciências contemporâneos para a educação científica formal. Rev. Bras. Ensino Fís., São Paulo, v. 30, n. 4, dez. 2008.

FREIRE, P. Pedagogia da autonomia: saberes necessários a prática educativa. São Paulo: Paz e Terra, p. 35. 2006.

GOHN, M. G. Educação não - formal, participação da sociedade civil e estruturas colegiadas nas escolas. Ensaio: aval. Pol. Públ. Educ., Rio deJaneiro, v. 14, n. 50, p. 27-38, 2006.

GONZÁLEZ REY, F. Pesquisa Qualitativa em Psicologia: Caminhos e desafios. Thomson: São Paulo. 2002.

GONZÁLEZ REY, F. L. Pesquisa qualitativa e subjetividade: Os processos de construção da informação. São Paulo: Pioneira Thomson Learning, 2005.

GONZÁLEZ REY, F. O sujeito que aprende:desafios do desenvolvimento do tema da aprendizagem na psicologia e na prática pedagógica. In. TACCA, M. C. Aprendizagem e trabalho pedagógico. Campinas: Alínea, 2008.

HOOPER-GREENHILL, E. Museum learners as active postmodernists: contextualizing constructivism. In: The Educational role of The Museum. Routledge, London, p. 67-72. 1994.

JACOBUCCI, D. F. C. Contribuições dos espaços não formais de educação para a formação da cultura científica. Em extensão, Uberlândia, v.7, 2008.

LIMA, V. M. R. Pesquisa em sala de aula:um olhar na direção do desenvolvimento da competência social. In R. M.; V. M. R. L. (Org.). Pesquisa em sala de aula: tendências para a Educação em Novos Tempos.2 ed. Porto Alegre: EDIPUCRS, v. 1, p. 275-291. 2004. 
MARTINS, M. C. (Org). Mediações: provocações estéticas. São Paulo: UNESP/Instituto de Artes/Pós-graduação, 2005.

MARANDINO, M. Perspectivas da Pesquisa Educacional em Museus de Ciências. In: SANTOS, F.M.T.; GREGA, I.M. (Org.). A Pesquisa em Ensino de Ciências no Brasil e suas Metodologias. ljuí, v. 1, p. 89-122, 2006.

MIZUKAMI, M. G. N. Formação de professores, práticas pedagógicas e escola.São Carlos: Ed. UFSCar, 2002.

MORAES, C. J. C. OLIVEIRA, C. M. GOLDSCHMIDT A. I. Elaboração de estratégias de ensino e uso dos estatutos do conhecimento: os obstáculos na construção do conhecimento de Ciências-Física. Amazônia. Revista de Educação em Ciências e Matemática. v.13 (28) Jul-Dez 2017. p.23-37.

OLIVEIRA. C. L. MOURA. D. C. Projeto Trilhos Marinhos - Uma abordagem de ambientes não formais de aprendizagem através da Metodologia de projetos. Educ. Tecnol. Belo Horizonte, v.10,n.2,p.46-51,jul/dez.2005.

OVIGLI, D. F. B. Prática de ensino de ciências: o museu como espaço formativo. Ensaio Pesquisa em Educação em Ciências, vol. 13, n. 13, 2011.

PIMENTA, S. G.; LIMA, M. S. L. Estágio e Docência: diferentes concepções. $5^{a}$ d. São Paulo: Cortez, 2010.

RAMOS, T. S, FREITAS, N. M. S, RAPOSO, E. O, FREITAS, N. M. S. Constructos em narrativas do ser e do se fazer docente. Revista de Educação em Ciências e Matemáticas, vol. 13, nº 25, 2016.

SCOZ, B. Psicopedagogia e Realidade Escolar: o problema escolar e de aprendizagem. 15ed. Petrópolis-RJ: Vozes, 2008.

SCOZ, B. J. L. Identidade e subjetividade de professoras/es: sentidos do aprender e do ensinar. 2a edição. Petrópolis: Vozes. Scoz, B. J. L. (2011). Identidade e subjetividade de professoras/es: sentidos do aprender e do ensinar. 2a edição. Petrópolis: Vozes. 2011.

TACCA, M. C. V. R. Estratégias pedagógicas: Conceituação e desdobramentos com foco nas relações professor-aluno. In: TACCA, M. C. V. R. (org.) Aprendizagem e trabalho pedagógico. Campinas-SP: Alínea, 2006. 